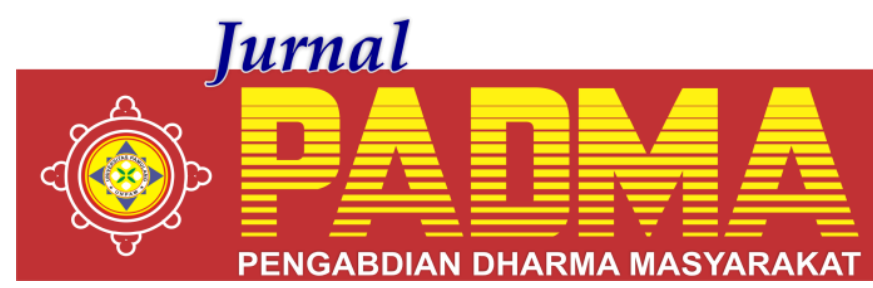

VOLUME I, NOMOR 4, OKTOBER 2021

\title{
MOTIVASI BELAJAR DAN MANAJEMEN WAKTU UNTUK ANAK PANTI YAYASAN MUTIARA IBU NUSANTARA (YASMIN)
}

\author{
${ }^{1 *}$ Arief Budi Santoso, ${ }^{2}$ Nuur Rasyiid Fatimah, ${ }^{3}$ Nadia Arisandi Davis, ${ }^{4}$ Siska Fauziah, \\ ${ }^{5}$ Nurlaila, ${ }^{6}$ Rien Filnalisi Siregar \\ Universitas Pamulang, Tangerang Selatan, Banten, Indonesia \\ *dosen01152@unpam.ac.id
}

\begin{abstract}
Abstrak
Dalam era globalisasi seperti sekarang ini, pendidikan merupakan hal terpenting dan suatu kebutuhan bagi setiap orang, karena melalui pendidikanlah seseorang dapat memperoleh ilmu pengetahuan. Motivasi memegang peranan yang penting dalam proses belajar. Apabila guru dan orang tua dapat memberikan motivasi yang baik pada siswa atau anaknya, maka dalam diri siswa atau anak akan timbul dorongan dan hasrat untuk belajar lebih baik. Memberikan motivasi yang baik dan sesuai, maka anak dapat menyadari akan manfaat belajar dan tujuan yang hendak dicapai dengan belajar tersebut. Motivasi belajar juga diharapkan mampu menggugah semangat belajar, terutama bagi para siswa yang malas belajar sebagai akibat pengaruh negative dari luar diri siswa. Dan Sekolah merupakan lembaga pendidikan formal sebagai sarana untuk mencapai tujuan pendidikan nasional. Seseorang yang berprestasi tinggi berhasil mengelola dan menerapkan penggunaan waktu mereka dengan sangat baik. Dengan menggunakan teknik manajemen waktu, dapat meningkatkan kemampuan seseorang untuk berfungsi lebih efektif bahkan ketika waktu terbatas dan mendapat tekanan. Manajemen waktu yang baik membutuhkan perubahan penting dalam fokus dari kegiatan untuk mendapatkan hasil nyata karena menjadi sibuk itu tidak sama dengan menjadi produktif.
\end{abstract}

Kata Kunci: Motivasi Belajar, Manajemen Waktu

\section{Abstract}

In this era of globalization, education is the most important thing and a necessity for everyone, because it is through education that one can gain knowledge. Motivation plays an important role in the learning process. If teachers and parents can provide good motivation to students or children, then in the student or child there will be encouragement and desire to learn better. Providing good motivation and appropriate, then the child can realize the benefits of learning and the goals to be achieved by learning. Learning motivation is also expected to encourage learning, especially for students who are lazy to learn as a result of negative influences from outside the students. And the School is a formal educational institution as a means to achieve national educational goals. A high achiever manages and applies their time usage very well. By using time management techniques, it can improve one's ability to function more effectively even when time is limited and under pressure. Good time management requires an important change in focus from activities to get real results because being busy is not the same as being productive.

Keywords: Learning Motivation, Time Management

\section{PENDAHULUAN}

Dalam dunia pendidikan, terutama dalam kegiatan belajar, dalam kelangsungan dan keberhasilan proses belajar mengajar bukan hanya dipengaruhi oleh faktor intelektual saja, melainkan juga oleh faktorfaktor nonintelektual lain yang tidak kalah penting dalam menentukan hasil belajar seseorang, salah satunya adalah kemampuan seseorang siswa untuk memotivasi dirinya. Motivasi sangat penting artinya dalam kegiatan belajar, sebab adanya motivasi mendorong semangat belajar dan sebaliknya kurang adanya motivasi akan melemahkan semangat belajar. Motivasi merupakan syarat mutlak dalam belajar; seorang siswa yang belajar tanpa motivasi (atau kurang motivasi) tidak akan berhasil dengan maksimal.

Manajemen Waktu, menurut Atkinson dilansir pada Gramedia.com, adalah suatu jenis keterampilan yang berkaitan dengan berbagai bentuk upaya dan tindakan individu yang dilakukan dengan terencana 
agar seseorang mampu memanfaatkan waktu sebanyak mungkin. Manajemen waktu merupakan penjadwalan, pengelompokan, dan penilaian terhadap produktifitas waktu.

Adanya manajemen waktu akan membantu proses pengerjaan menjadi lebih efektif dan efisien. Efektifitas bisa diamati dari bagaimana tercapainya tujuan untuk memanfaatkan waktu sebagaimana yang telah dijadwalkan sebelumnya. Sedangkan efisiensi bisa diamati dari bagaimana sesuatu itu dilakukan dengan waktu yang lebih singkat atau boros. Manajemen waktu ini sangat penting diaplikasikan dalam kehidupan sehari-hari. baik untuk kepemimpinan, bekerja, menjalankan bisnis, dan belajar.

\section{METODE}

Metode dalam kegiatan Pengabdian Kepada Masyarakat ini adalah dengan memberikan penyuluhan sosialisai kepada anak-anak Yayasan tersebut, yang bertujuan untuk meningkatkan pengetahuan tentang Motivasi Belajar dan Manajemen Waktu dalam kehidupan sehari-hari.

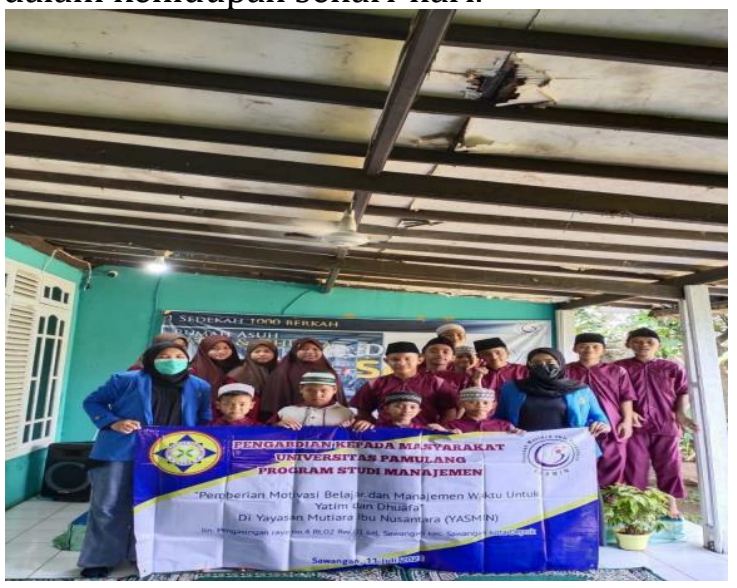

Gambar 1

\section{HASIL DAN PEMBAHASAN}

kegiatan dilaksanakn melalui penjelasan materi, diskusi, tanya jawab, serta melakukan penyuluhan dalam upaya meningkatkan kreativitas kepada para santri. Kegiatan berjalan dengan baik dan lancar, serta para santri sangat berantusias dalam mengikuti kegiatan.

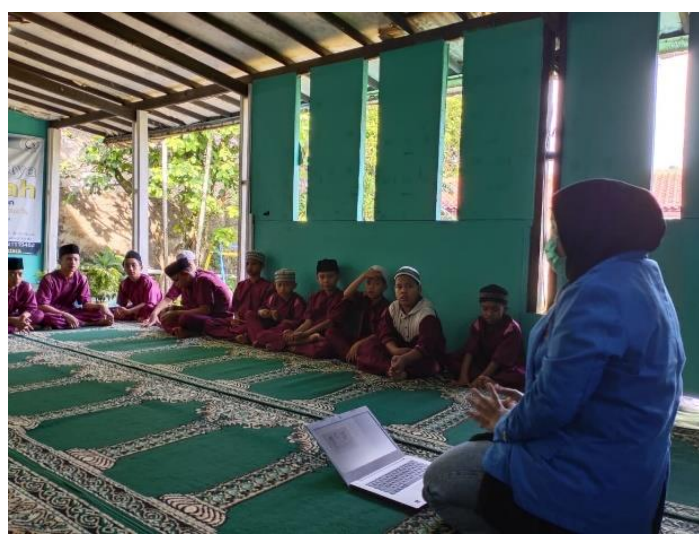

Gambar 2

\section{PENUTUP}

Pengabdian Kepada Masyarakat ini dilakukan di Yayasan Mutiara Ibu Nusantara (YASMIN), dalam bentuk sosialisasi secara langsung namun tetap memperhatikan protokol kesehatan. Harapan kami dengan terlaksananya kegiatan ini dapat menambah wawasan serta pengetahuan anak-anak yang berada di yayasan tersebut, khususnya mengenai Motivasi Belajar dan Manajemen Waktu. Dalam laporan kegiatan ini mungkin banyak kekurangan yang terdapat didalamnya, untuk itu kami berharap masukan dan kritikan dalam rangka perbaikan untuk kegiatan-kegiatan masyarakat yang akan datang, namun tetap memperhatikan protocol kesehatan.

\section{DAFTAR PUSTAKA}

Artikel/motivasi-belajar-80.

Disdikpora. (2016). Motivasi Belajar, https://disdikpora.bulelengkab.go.id/ informasi/detail/

Elburdah, R. P. (2019). Jurnal Abdimas, Penggunaan Manajemen Waktu Terhadap Peningkatan Presentasi Belajar Di SMP ARAISIYAH. 3-5. file://C:/Users/User/Pictures/40428362-1-SM.pdf

https:/

core.ac.uk/download/pdf/324200489 .pdf. 9c2/pentingnya-manajemenwaktu-dalam belajar

Kecakapan Hidup Siswa, 123Nurhidayati, D. D. (2016). PSIKOPEDAGOGIA, Peningkatan Pemahaman Manajemen Waktu Melalui Bimbingan Kelompok Dengan Teknik Problem Solving Pada Siswa 26. 
Kiswoyowati, A. (2011). Pengaruh Motivasi Belajar dan Kegiatan Belajar Siswa Terhadap

Kompasiana (2021). Pentingnya Manajemen Waktu dalam Belajar, https://www.KompaSiana.com/viona kesya/60f156c106310e05fb3b

Muslimat, A., et al. (2021). Develop Technology Based Multimedia For
Indonesian Teachers. Journal of Contemporary Issues in Business and Government, 27(1), 1871-1882.

Sobarna, A., et al. (2020). The Effect of Pedagogic Competence Kids Athletic toward Motivation for Elementary School. Solid State Technology, 63(6), 1364-1371. 